\title{
Multiphysical mathematical models for design, identification and diagnostics of high-precision positioning systems
}

\author{
Anton M. Lankin, Mariya Y. Lankina*, and Mikhail V. Lankin \\ Platov South-Russian State Polytechnic University, 346400 Novocherkassk, Russia
}

\begin{abstract}
A multi-physical model was implemented in the software package LabView. Its choice is due to the need to solve the developed system of equations in an implicit form. LabView is a graphical simulation environment that allows you to build dynamic models, including discrete, continuous and hybrid, non-linear and discontinuous systems, using block diagrams in the form of directed graphs. These capabilities of the program confirm the need for its selection as a modeling environment.
\end{abstract}

\section{Introduction}

It is difficult to name the field of technology, where no high-precision systems are used. They are contained in many household appliances, communication devices, are an integral part of electrical machines, many industrial automation devices, control and protection equipment for various electrical installations. To carry out a model simulation experiment, models that relate the parameters of high-precision systems of different physical nature [1-6].

A model-natural experiment allows to achieve the coincidence of the greatest number of the model and the object parameters [7, 8]. It combines the measurement of a physical object and the modeling of the processes taking place in this object with the means of a personal computer. In our case, the high-precision system is the physical object for carrying out the model simulation experiment. High-precision systems are the combination of precision mechanics and modern electric, electronic and computer control elements. Thus, in case of a natural-model experiment, it is required to construct multi-physical models linking the electrical, magnetic, and mechanical processes that occur in them. To consider the reliability of high-precision systems thermal processes must to be taken into account. Thus multi-physical model of high-precision systems is a system of equations:

$$
\begin{cases}P \text { elec }=f 1(U, I, R, \psi), & \text { electrical processes } \\ P \operatorname{mag}=f 2(\psi, B(H), I, G), & \text { magnetic processes } \\ P \text { mech }=f 3(m, x, G, I), & \text { mechanical processes } \\ P \text { ther }=f 4(T, Q, I, G), & \text { thermal processes }\end{cases}
$$

\footnotetext{
* Corresponding author: semenchenko-mariya@mail.ru
} 
where Pelec, Pmag, Pmech, Pther - dependent model parameters, $f$ - independent parameters of the model: $U$-voltage, $I$ - current, $R$ - resistance, $\psi$-magnetic flux, $B(H)-$ magnetic characteristics, $m$ - weight, $x$ - gap, $G-$ generalized dimensional figure, $T-$ temperature, $Q$ - thermal energy.

The type and parameters of such multi-physical model can be found basing on the description of physical processes of interaction and can be determined by statistical methods using the results of a number of measurements.

\section{Methods and researches}

Let us consider the first way of constructing a multiphysical model. As an example of a high-precision system, the proportional electromagnet of the hydraulic distributor (Figure 1). The performance of the entire drive depends on the quality of the proportional electromagnet [9-11].
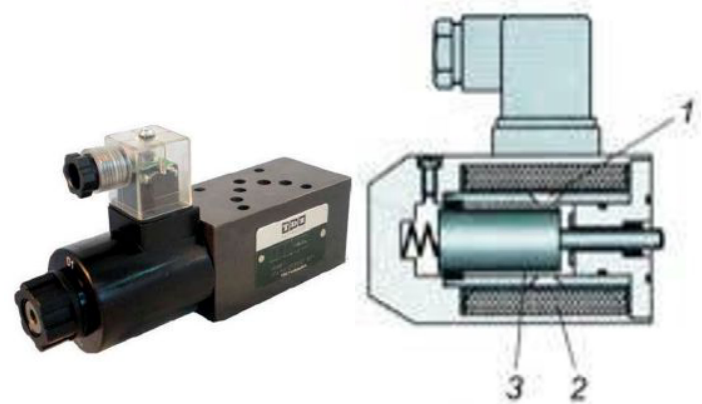

Fig. 1. Proportional electromagnet of the hydraulic distributor

To build a model, let us consider the basic characteristics of a proportional electromagnet describing the various physical processes taking place in it. Let us analyze the processes occurring in the electromagnet during its operation and construct a general mathematical model reflecting the physical processes taking place in the chosen highprecision system:

The expression describing the electromagnetic force has the form:

$$
F_{3}=\frac{\psi^{2}}{2 \mu_{0} S w^{2}},
$$

where, $\mu_{0}$ - the magnetic constant is equal to $4 \pi \cdot 10-7 \mathrm{G} / \mathrm{m}, S$ - anchor end area, $\psi$ - flux linking of turns of the working winding of an electromagnet with a magnetic flux, $w-$ number of turns of working winding.

Static traction characteristic $F_{\mathrm{c}}=f 1(\delta)$ with considering (1.1) has the form

$$
F_{\mathrm{c}}=\frac{\psi(\delta)^{2}}{2 \mu_{0} S w^{2}} .
$$

Dynamic traction characteristic $F_{\mathrm{d}}=f 2(\delta)$ has the form 


$$
F_{\text {д }}=\frac{1}{2 \mu_{0} S}\left(\left(\frac{\psi(\delta)}{w}\right)^{2}+2 \psi(\delta) u(t) t+\left(\frac{u(t) t}{w}\right)^{2}\right),
$$

where $t$ - time, $u(t)$ - voltage applied to the working winding of an electromagnet.

As is known, the equation of motion of the armature of an electromagnet has the form:

$$
m \frac{d^{2} x}{d t^{2}}=F_{\mathrm{e}}-F_{\mathrm{p}}-F_{\mathrm{c}}\left(\frac{d x}{d t}\right),
$$

where $m$ - reduced mass of moving parts; $F_{\mathrm{e}}$ - force acting on the armature of the electromagnet from the side of the electromagnetic field created by the working winding of the electromagnet, $F_{\mathrm{p}}$ - reaction force; $F_{\mathrm{c}}(d x / d t)$ - force of resistance, depending on the speed of motion (frictional force).

The equation of the electric circuit of the working winding of the electromagnet has the form:

$$
u(t)=i(t) R+\frac{d \psi}{d t}
$$

where $R$-active component of the resistance of the working winding of an electromagnet; $\frac{d \psi}{d t}$ - rate of change of flux linkage.

Let us find from (1.4) the current flowing through the working winding of the electromagnet

$$
i(t)=\frac{\left(u(t)-\frac{d \psi}{d t}\right)}{R} .
$$

Characteristics of the change in the temperature of an electromagnet during its heating and cooling

$$
T=f_{5}\left(P, t_{\text {on }}, G\right)
$$

shows the relationship between the characteristic of the dependence of the change in the heating temperature and the cooling of the electromagnet in $T=f_{5}(t)$ with electrotechnical parameters of the electromagnet: power $P$, in the winding, the dimensions of the electromagnet $G$ and on time $t_{\text {on }}$.

Dependence of magnetic flux on current $\Phi=f_{6}(i, \delta)$ at fixed values of the gap $\delta$ between the armature and the yoke of the electromagnet can be expressed through the dependence of the flux linkage on the current and gap $\psi=f_{7}(I, \delta)$ :

$$
\Phi=\frac{\psi}{w}
$$

Thus, the general multiphysical model has the following form [12-17]: 


$$
\left\{\begin{array}{l}
F_{\mathrm{c}}=\frac{\psi(\delta)^{2}}{2 \mu_{0} S w^{2}} \\
F_{\text {д }}=\frac{1}{2 \mu_{0} S}\left(\left(\frac{\psi(\delta)}{w}\right)^{2}+2 \psi(\delta) u(t) t+\left(\frac{u(t) t}{w}\right)^{2}\right) \\
m \frac{d^{2} x}{d t^{2}}=F_{\mathrm{e}}-F_{\mathrm{p}}-F_{\mathrm{c}}\left(\frac{d x}{d t}\right) ; \\
i(\mathrm{t})=\frac{\left(u(\mathrm{t})-\frac{d \psi}{d t}\right)}{R} \\
T=f_{5}\left(P, t_{\mathrm{on}}, G\right) ; \\
\Phi=\frac{\psi}{w} .
\end{array}\right.
$$

This model connects the parameters of proportional electromagnets of different physical nature, reflecting the quality of work in proportion to the electromagnet.

A multi-physical model was implemented in the software package LabView. Its choice is due to the need to solve the developed system of equations in an implicit form. LabView is a graphical simulation environment that allows you to build dynamic models, including discrete, continuous and hybrid, non-linear and discontinuous systems, using block diagrams in the form of directed graphs. These capabilities of the program confirm the need for its selection as a modeling environment.

The developed model includes electric, magnetic and mechanical processes occurring in a proportional electromagnet:

$$
\left\{\begin{array}{l}
u(t)=i(t) R+\frac{d \psi}{d t} \\
i(\Phi)=\sum_{1}^{m} k_{q} \Phi^{q} \\
m \frac{d^{2} x}{d t^{2}}=F_{\mathrm{e}}-F_{\mathrm{p}}-F_{\mathrm{c}}\left(\frac{d x}{d t}\right)
\end{array}\right.
$$

This model is built on statistical data and allows to obtain the functions of flux linkage, voltage and displacement based on current measurement. To adjust the model, we used data (statistical sampling) obtained on real proportional electromagnets of the same type (Figure 2).

Input parameters of the model:

$i$ - current in the winding of a proportional electromagnet. Measured on a controlled electromagnet after adjusting the model.

Parameters for setting up the model:

$R$ - resistance of the winding of a proportional electromagnet. Determined from the statistical sample $i(t)$ and $u(t)$.

$k_{q}$ - coefficients of approximation of DCM. Determined from the statistical sample $i(t)$ and $\Phi(t)$. 
$F_{\mathrm{p}}$ - force of the reaction mechanism. It is found as a regression on the principal components of the statistical sample $x(t)$ and $\Phi(t)$.

Output parameters of the model:

$\Phi-$ magnetic flux.

$u$ - voltage on the winding of a proportional electromagnet.

$x$ - armature movement.

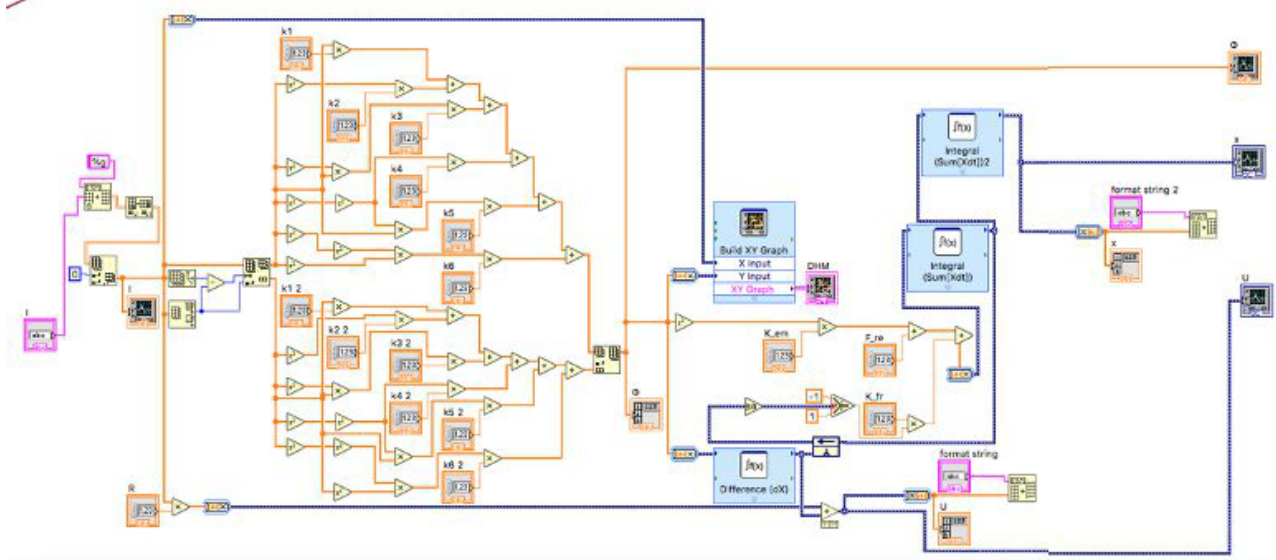

Fig.2. Model of the selected high-precision system reflecting the magnetic, electrical and mechanical processes

An example of this model is shown in the following Figure 3.

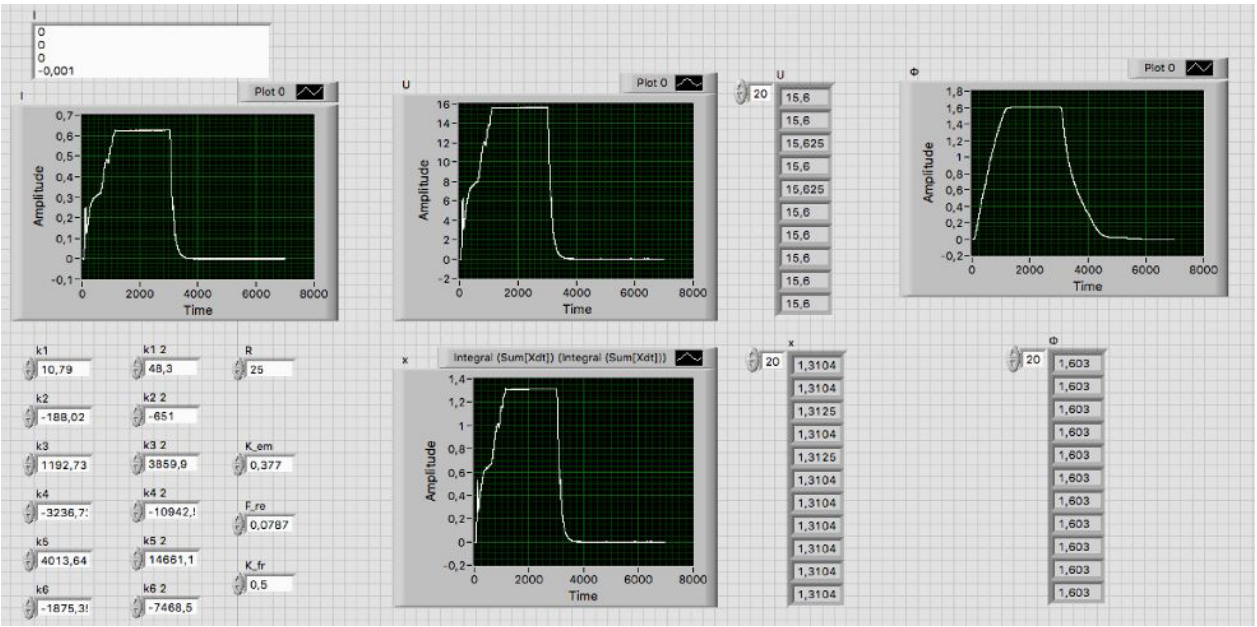

Fig.3. The interface of the model of the selected high-precision system in LabView

The use of this model allows express-diagnostics of the state of proportional electromagnets of hydraulic drives, by measuring and setting in the model only time-current characteristics.

For such express-diagnostics [18-20], you can also apply the elements of the main component method. A software product has been developed that allows one to determine the type of defect of a proportional electromagnet in the form of current and the form of flux linkage. 


\section{Conclusion}

Thus, during the work the following tasks were performed:

1. The review and analysis of methods of mathematical modeling of various physical processes in high-precision systems is carried out. As an example of a high-precision system, proportional electromagnets of hydraulic drives are chosen. The processes occurring in the proportional electromagnet during its operation are investigated. The main electrotechnical parameters and performance characteristics of proportional electromagnets.

2. The applicability of the principal component method for eliminating the phenomenon of multicollience in the construction of multi-physical models is investigated. Developed software in Labview that implements the method of the main components. We consider multiphysical models based on statistical data sets.

3. Multiphysical models of the chosen high-precision system have been developed. The models are implemented in the software Labview.

4. The applicability of the Labview simulation environment for implementing the developed multiphysical model is investigated. The principles of constructing models in Labview are considered and a model consisting of equations describing the electric and magnetic processes in the selected high-precision system.

5. Implementation of the developed multiphysical model in the form of a software product in the Labview environment.

6. Investigation of a software product in the Labview environment using an example of a specific high-precision system.

The results of the work were obtained with the support of the project No. 2.7193.2017/8.9 "Development of the scientific basis for designing, identifying and diagnosing high- precision positioning systems using the inverse electrical engineering methodology", performed within the framework of the main parts of the state task. The results of the work were obtained using the equipment of the collective use center "Diagnostics and Energy-Efficient Electrical Equipment" of the YRSU Platov South-Russian State Polytechnic University (NPI).

\section{References}

1. A.M. Lankin, M.V. Lankin, M.Y. Lankina, IOP Conf. Ser.: MSE, 10, 012074 (2017)

2. N.I. Gorbatenko, M.V. Lankin, Elektrotekhnika 8, 55 (2004)

3. A. Lankin, D. Shaykhutdinov, V. Grechikhin, D. Schuchkin, N. Narakidze,

N. Gorbatenko, Jour. of Eng. and Appl. Sci., 12(2), 363 (2017)

4. B.T. Polyak, M.V. Khlebnikov, Automation and Telemechanics, 3, 130 (2017)

5. V.V. Grechikhin, M.V. Lankin, A.M Lankin, Prom-Eng. WISTC, 235 (2015)

6. N.I. Gorbatenko, A.M. Lankin, M.V. Lankin, Procedia Engineering, 129, 799 (2015)

7. A.M. Lankin, M.V. Lankin, M.Y. Lankina, IOP Conf. Ser.: MSE, 10, 012075 (2017)

8. N.I. Gorbatenko, A.M. Lankin, M.V. Lankin, D.V. Shayhutdinov, Inter. Jour. of Appl. Eng. Res., 10(3), 6509 (2015)

9. A.M. Lankin, M.V. Lankin, N.I. Gorbatenko, D.V. Shayhutdinov, MAS, 9(8), 247 (2015)

10. D.V. Shaikhutdinov, A.M. Lankin, N.D. Narakidze, V.V. Grechikhin, K.M. Shirokov, N.I. Gorbatenko, Res. Jour. of Appl. Sci., 10(10), 555 (2015)

11. A.M. Lankin, M.V. Lankin, V.V. Grechikhin, D.V. Shaikhutdinov, Res. Jour. of Appl. Sci., 10(10), 695 (2015) 
12. N.I. Gorbatenko, A.M. Lankin, M.V. Lankin, Procedia Engineering, 150, 1027 (2016)

13. A.M. Lankin, M.V. Lankin, O.A. Naugolnov, Procedia Engineering, 150, 1020 (2016)

14. N.I. Gorbatenko, A.M. Lankin, M.V. Lankin, Met. Sci. and Heat Treat., 1 (2017)

15. N.I. Gorbatenko, A.M. Lankin, M.V. Lankin, Met. Sci. and Heat Treat., 4 (2017)

16. N.I. Gorbatenko, V.V. Grechikhin, M.V. Lankin, A.M. Lankin, Meas. Tech., 59(7), 747 (2016)

17. A.M. Lankin, M.V. Lankin, Nat. Ass. of Sch., 4-2 (9), 132 (2015)

18. A.M. Lankin, Mod. high tech., 9-3, 420 (2016)

19. A.M. Lankin, Bas. res., 9-3, 495 (2016)

20. M.V. Lankin, A.M. Lankin, IOP Conf. Ser.: MSE, 10, 012031 (2016) 